\title{
Green chemistry approach for the synthesis of biocompatible graphene
}

\author{
This article was published in the following Dove Press journal: \\ International Journal of Nanomedicine \\ 30 July 2013 \\ Number of times this article has been viewed
}

\section{Sangiliyandi Gurunathan Jae Woong Han \\ Jin-Hoi Kim}

Department of Animal Biotechnology, Konkuk University, Seoul, South Korea
Correspondence: Sangiliyandi Gurunathan; Jin-Hoi Kim

Department of Animal Biotechnology, Konkuk University, I Hwayang-Dong,

Gwangin-gu, Seoul, |43-70I

Email gsangiliyandi@yahoo.com;

jhkim54I@konkuk.ac.kr
Background: Graphene is a single-atom thick, two-dimensional sheet of hexagonally arranged carbon atoms isolated from its three-dimensional parent material, graphite. One of the most common methods for preparation of graphene is chemical exfoliation of graphite using powerful oxidizing agents. Generally, graphene is synthesized through deoxygenation of graphene oxide (GO) by using hydrazine, which is one of the most widespread and strongest reducing agents. Due to the high toxicity of hydrazine, it is not a promising reducing agent in large-scale production of graphene; therefore, this study focused on a green or sustainable synthesis of graphene and the biocompatibility of graphene in primary mouse embryonic fibroblast cells (PMEFs).

Methods: Here, we demonstrated a simple, rapid, and green chemistry approach for the synthesis of reduced $\mathrm{GO}$ ( $\mathrm{rGO}$ ) from GO using triethylamine (TEA) as a reducing agent and stabilizing agent. The obtained TEA reduced GO (TEA-rGO) was characterized by ultraviolet (UV)-visible absorption spectroscopy, X-ray diffraction (XRD), particle size dynamic light scattering (DLS), scanning electron microscopy (SEM), Raman spectroscopy, and atomic force microscopy (AFM).

Results: The transition of graphene oxide to graphene was confirmed by UV-visible spectroscopy. XRD and SEM were used to investigate the crystallinity of graphene and the surface morphologies of prepared graphene respectively. The formation of defects further supports the functionalization of graphene as indicated in the Raman spectrum of TEA-rGO. Surface morphology and the thickness of the GO and TEA-rGO were analyzed using AFM. The presented results suggest that TEA-rGO shows significantly more biocompatibility with PMEFs cells than GO.

Conclusion: This is the first report about using TEA as a reducing as well as a stabilizing agent for the preparation of biocompatible graphene. The proposed safe and green method offers substitute routes for large-scale production of graphene for several biomedical applications.

Keywords: graphene oxide, graphene, triethylamine, ultraviolet-visible spectroscopy, Raman spectroscopy, atomic force microscopy

\section{Introduction}

Graphene is a two-dimensional (2D) atomic crystal which consists of carbon atoms arranged in a hexagonal lattice. ${ }^{1-3}$ Graphene and related nanomaterials have received considerable attention due to their high surface area and unique physical and chemical properties. ${ }^{4}$ This unique chemical structure gives graphene excellent electrical, mechanical, and optical properties, thus attracting much commercial and academic research interest. ${ }^{2}$ Therefore, many synthetic strategies for graphene have been developed with the goal of making large quantities of high-quality graphene in a cost effective manner. ${ }^{5}$ For the synthesis of high quality graphene, epitaxial growth and chemical vapor deposition methods are generally employed; however, these methods are not compatible with 
large-scale synthesis in solution-processable form and they require expensive high-temperature processes. ${ }^{6,7}$ Effective and scalable approaches are essential processes required for various practical applications of graphene. ${ }^{1}$ However, most applications depend on availability of processable reduced graphene oxide (rGO) in large quantities; therefore, the development of efficient and cost-effective approaches has been the focus of substantial attention. Several methodologies are available, including micromechanical exfoliation ${ }^{2}$ and chemical reduction of graphene oxide (GO). ${ }^{8,9}$ Although several techniques are available, the chemical reduction of GO has proven to be a promising method due to its low cost, the ease of bulk quantity production, and because it is well suited for chemical modification and subsequent processing. ${ }^{10-13}$ In general, hydrazine and hydrazine derivatives were usually employed as a strong reducing agent in the formation of graphene with high conductivity. ${ }^{11-16}$ The majority of the reducing agent is either toxic or explosive and is difficult to handle in larger scale production.

However, strong and toxic reduction agents and surfactants are essential to reduce GO fully in an aqueous phase. ${ }^{17}$ To solve this problem, many studies have attempted to develop a new aqueous and environmentally-friendly reduction strategy using bacterial respiration, ${ }^{18}$ polyallylamine, ${ }^{19}$ potassium hydroxide $(\mathrm{KOH}),{ }^{20}$ polyvinylpyrrolidone,${ }^{21}$ ascorbic acid, ${ }^{22}$ sugar, ${ }^{23}$ Baker's yeast, ${ }^{24}$ and protein. ${ }^{25}$ Among the various nontoxic reduction agents, protein has significant advantages because adsorbed proteins can be harnessed as a universal type of glue for various nanomaterials used in nanocomposite synthesis. Dextran is used as a multifunctional agent for GO reduction and functionalization. ${ }^{26}$ Recently, our group developed an environmentallyfriendly and simple approach for synthesis of water soluble graphene. ${ }^{27-29}$

Several studies have been published regarding toxicity of graphene both in bacteria and human cell types. The effect of GO and rGO on the growth of Escherichia coli has been noted, and they have been observed with minimal toxicity in human alveolar epithelial A549 cells as well. ${ }^{30}$ Akhavan and Ghaderi $^{31}$ compared the toxicity levels of graphene and GO nanowalls in E. coli and Staphylococcus aureus bacteria and found that $\mathrm{GO}$ and $\mathrm{rGO}$ caused bacterial membrane damage and that the hydrazine-rGO was more toxic than untreated GO. Akhavan et $\mathrm{al}^{32}$ investigated the cytotoxic effects of the graphene incorporated in the titanium oxide $\left(\mathrm{TiO}^{2}\right)$ film against Caenorhabditis elegans nematodes, as a simple and well-established animal model, under solar light-induced stress conditions. Zhang et $\mathrm{al}^{33}$ demonstrated that both GO and carbon nanotubes (CNTs) induced cytotoxic effects on pheochromocytoma (PC-12) cells; the authors concluded that CNTs are more toxic than graphene and that the shape of these carbon-based nanomaterials plays an important role in their cytotoxicity. Recently, Wang et $\mathrm{al}^{34}$ demonstrated that GO has dose-dependent toxicity to human fibroblast cells, with GO causing obvious toxicity when the dose was higher than $50 \mu \mathrm{g} / \mathrm{mL}$. Chang et al ${ }^{35}$ suggested GO will not enter A549 cells and that GO shows no obvious toxicity to A549 cells, regardless of the size or dose of GO. Liao et al ${ }^{36}$ demonstrated the biocompatibility of graphene-related materials with controlled physical and chemical properties and also explained that the toxicity of graphene and GO depends on their exposure environment. Further, Akhavan et al ${ }^{37}$ demonstrated the size-dependent cytotoxic and genotoxic effects of the reduced graphene oxide nanoplatelets on human mesenchymal stem cells (hMSCs).

Regarding biocompatibility of graphene materials, Yan et $\mathrm{al}^{38}$ developed free-standing GO-Polyaniline(PANI) and graphene-PANI hybrid papers via rapid mixture polymerization of aniline on the surfaces of GO and graphene papers; these exhibit excellent biocompatibility, flexibility, electrochemical activity. Liu et $\mathrm{al}^{39}$ have developed GO-based glucose sensors and have also shown excellent reproducibility and significant biocompatibility to human retinal pigment epithelial cells. In recent years, graphene sheets with various lateral dimensions have been applied in tissue engineering as scaffolds to support cellular attachment, proliferation, and differentiation ${ }^{40-42}$ in photothermal cancer therapy, as they are excellent near infrared (NIR) absorbent nanomaterials. ${ }^{43,44}$ Chen et $\mathrm{al}^{45}$ have developed biocompatible, mechanically strong, electrically conductive graphene paper; its preliminary cytotoxicity tests suggest that biocompatibility of this material would result in attractive potential applications. Park et $\mathrm{al}^{46}$ have fabricated a strong and biocompatible freestanding paper composed of Tween 20 and chemically reduced GO, which exhibits excellent stability in water. The Tween 20 paper and the rGO paper were noncytotoxic to three mammalian cell lines, while only the Tween 20 paper inhibited the nonspecific binding (NSB) of bacterial cells. Functionalized graphene shows excellent compatibility with red blood cells, platelets, and plasma coagulation pathways, and minimal alteration in the cytokine expression by human peripheral blood mononuclear cells. ${ }^{47}$ Singh et $\mathrm{al}^{48}$ have demonstrated that amine-modified graphene $\left(\mathrm{G}-\mathrm{NH}^{2}\right)$ had neither a stimulatory effect on human platelets, nor did it induce pulmonary thromboembolism in mice. 
In this study, we used primary mouse embryonic fibroblasts (PMEFs) as a model system. In broad-spectrum, PMEFs are used in the culturing of mouse embryonic stem (ES) cells, providing both a substrate for the ES cells to grow on and secreting many factors necessary for ES cells to maintain pluripotency. In addition, PMEFs cells are capable of undergoing a limited number of population doublings before entering crisis and senescence-like growth arrest; they are the ideal model system for studying aspects of cell growth control and functional aspects.

Synthesis of biocompatible graphene is essential for various biomedical applications. Herein, we demonstrate a simple, quick, and room temperature-mediated synthesis of highly soluble graphene using triethylamine (TEA); we also investigate the biocompatibility of synthesized graphene in PMEFs.

\section{Materials and methods Materials}

Graphite powder was purchased from Sigma-Aldrich (St Louis, MO, USA). TEA, sodium hydroxide $(\mathrm{NaOH})$, potassium permanganate $\left(\mathrm{KMnO}_{4}\right)$, anhydrous ethanol, $98 \%$ sulfuric acid $\left(\mathrm{H}_{2} \mathrm{SO}_{4}\right), 36 \%$ hydrochloric acid $(\mathrm{HCl})$, and $30 \%$ hydrogen peroxide $\left(\mathrm{H}_{2} \mathrm{O}_{2}\right)$ aqueous solution were purchased from Sigma-Aldrich and used directly without further purification. All aqueous solutions were prepared with deionized (DI) water. All other chemicals were purchased from Sigma-Aldrich unless stated otherwise.

\section{Synthesis of GO}

Natural graphite powder was utilized as the raw material to prepare graphite oxide according to suspension using a modified Hummers' method ${ }^{10}$ and Esfandiar et al. ${ }^{49}$ The prepared graphite oxide powder was dispersed in DI water to obtain an aqueous graphite oxide suspension with a yellow-brownish color. The suspension was centrifuged at $3000 \mathrm{rpm} /$ minute for 10 minutes to eliminate unexfoliated graphitic plates, and then at $10,000 \mathrm{rpm} /$ minute for 10 minutes to remove tiny graphite particles. Finally, GO suspension was achieved by exfoliation of the filtered graphite oxide suspension through its sonication.

\section{Reduction of GO by TEA}

Reduction of GO was followed as described earlier. ${ }^{49} \mathrm{rGO}$ was obtained from the reaction of TEA with GO. Typically, the final concentration of $0.1 \%(\mathrm{v} / \mathrm{v})$ TEA was dissolved in $20 \mathrm{~mL}$ GO aqueous suspension $(0.1 \mathrm{mg} / \mathrm{mL})$ and then the mixture was kept in a tightly sealed glass bottle and stirred at $30^{\circ} \mathrm{C}$ for 1 hour. Using a magneto-stirrer heater, TEA-GO suspension was then stirred at $400 \mathrm{rpm}$, at a temperature of $30^{\circ} \mathrm{C}$, for 30 minutes. A homogeneous TEA-rGO suspension was obtained without aggregation. Finally, the functionalized TEA-rGO was filtered and washed with DI water.

\section{Characterization}

Ultraviolet-visible (UV-vis) spectra were recorded using a WPA (Biowave II; Biochrom, Cambridge, UK). The aqueous suspension of GO and TEA-rGO was used as the UV-vis sample and the DI water was used as a reference. The particle size of dispersions was measured by Zetasizer Nano ZS90 (Malvern Instruments, Malvern, UK). X-ray diffraction (XRD) analyses were carried out on an X-ray diffractometer (Bruker D8 DISCOVER, Bruker AXS GmBH, Karlsruhe, Germany). The high resolution XRD patterns were measured at $3 \mathrm{~kW}$ with $\mathrm{Cu}$ target using a scintillation counter $\left(\lambda=1.5406^{\circ} \mathrm{A}\right)$ at $40 \mathrm{kV}$ and $40 \mathrm{~mA}$; they were recorded in the range of $2 \theta=5^{\circ}-80^{\circ}$. The solid samples were transferred to a carbon tape held in a scanning electron microscopy (SEM) sample holder for analyses. The analyses of the samples were carried out at an average working distance of $6 \mathrm{~mm}$. Raman spectra of GO and rGO were measured by WITEC Alpha300 (Witec, Ulm, Germany) with a $532 \mathrm{~nm}$ laser. The calibration was initially made using an internal silicon reference at $500 \mathrm{~cm}^{-1}$ and gave a peak position resolution of less than $1 \mathrm{~cm}^{-1}$. The spectra were measured from $500-4500 \mathrm{~cm}^{-1}$. All samples were deposited on glass slides in powder form without using any solvent. Surface images were measured using tapping mode atomic force microscopy (TM-AFM) (SPA 400, SEIKO Instruments, Chiba, Japan) operating at room temperature. Height and phase images were recorded simultaneously using nanoprobe cantilevers (SI-DF20, SEIKO Instruments).

\section{Cell culture and exposure to GO and TEA-rGO}

PMEFs cells were routinely cultured in Dulbecco's Modified Eagle's low glucose medium (DMEM/low, Life Technologies, Carlsbad, CA, USA) supplemented with $10 \%(\mathrm{v} / \mathrm{v})$ fetal bovine serum (FBS), plus $2 \mathrm{mM}$ L-glutamine, $1 \%(\mathrm{v} / \mathrm{v})$ penicillin-streptomycin $(10 \mathrm{U} /$ $\mathrm{mL}$ penicillin and $0.1 \mathrm{mg} / \mathrm{mL}$ streptomycin); they were grown at $37^{\circ} \mathrm{C}$ in a $5 \%$ carbon dioxide $\left(\mathrm{CO}_{2}\right)$ humidified environment. When the cells had reached $70 \%$ confluence, they were trypsinized $(0.25 \%$ Trypsin- $0.04 \%$ ethylenediaminetetraacetic acid [EDTA], Sigma-Aldrich) and 
passaged (1:3). Cells within three passages were used for experiments. GO or TEA-rGO suspensions were freshly prepared before the cells were exposed and diluted to appropriate concentrations from $20-100 \mu \mathrm{g} / \mathrm{mL}$ with the culture medium, then immediately applied to the cells. Cells that were not treated with GO or TEA-rGO served as controls in each experiment.

\section{Cell viability assay}

WST-8 assay was followed as described earlier by Liao et al. ${ }^{36}$ Typically, $1 \times 10^{4}$ cells were seeded in a 96-well plate and cultured in DMEM supplemented with $10 \%$ serum at $37^{\circ} \mathrm{C}$ under $5 \% \mathrm{CO}_{2}$. After 24 hours, the cells were washed with $100 \mu \mathrm{L}$ of serum-free DMEM two times and incubated with $100 \mu \mathrm{L}$ of different concentrations of GO or TEA-rGO suspensions in serum-free DMEM. After 24 hours exposure, the cells were washed twice with serumfree DMEM and $15 \mu \mathrm{L}$ of WST-8 solution was added to each well containing $100 \mu \mathrm{L}$ of serum-free DMEM. After 1 hour incubation at $37^{\circ} \mathrm{C}$ under $5 \% \mathrm{CO}_{2}, 80 \mu \mathrm{L}$ of the mixture was transferred to another 96-well plate, because residual GO or TEA-rGO can affect the absorbance values at $450 \mathrm{~nm}$. The absorbance of the mixture solutions was measured at $450 \mathrm{~nm}$ using a microplate reader. Cell-free control experiments were performed to see if the GO and rGO reacted directly with the WST- 8 reagents. Typically, $100 \mu \mathrm{L}$ of GO or TEA-rGO suspensions with different concentration $(20-100 \mu \mathrm{g} / \mathrm{mL})$ were added to a 96 -well plate and $10 \mu \mathrm{L}$ of WST- 8 reagent solution was added to each well; the mixture solution was incubated at $37^{\circ} \mathrm{C}$ under $5 \% \mathrm{CO}_{2}$ for 1 hour. After incubation, the $\mathrm{GO}$ or TEA-rGO were centrifuged and $50 \mu \mathrm{L}$ of supernatant was transferred to another 96-well plate. The optical density was measured at $450 \mathrm{~nm}$.

\section{Membrane integrity}

Cell membrane integrity of PMEFs cells was evaluated by determining the activity of lactate dehydrogenase (LDH) leaking out of the cell, according to the manufacturer's instructions for the in vitro toxicology assay kit (TOX7, Sigma-Aldrich). The LDH assay is based on the release of the cytosolic enzyme, LDH, from cells with damaged cellular membranes. Thus, in cell culture, the course of GO and TEA-rGO induced cytotoxicity was followed quantitatively by measuring the activity of LDH in the supernatant. Briefly, cells were exposed to various concentrations of $\mathrm{GO}$ and TEA-rGO for 24 hours and then $100 \mu \mathrm{L}$ per well of each cell-free supernatant was transferred in triplicate into wells in a 96-well plate; $100 \mu \mathrm{L}$ of $\mathrm{LDH}$-assay reaction mixture was then added to each well plate. After a 3-hour incubation under standard conditions, the optical density of the color generated was determined at a wavelength of $490 \mathrm{~nm}$ using a microplate reader.

\section{Cell population growth assay}

The cell population growth assay followed the method described earlier. ${ }^{50}$ Cells were plated in six well culture plates at a density of $1 \times 10^{4} /$ well in $1 \mathrm{~mL}$ of DMEM supplemented with $10 \%$ FBS. The cells were allowed to attach and media were replaced with various concentrations of GO or TEArGO $(0-20 \mu \mathrm{g} / \mathrm{mL})$ in triplicate. After treatment with three experimental conditions for 24 hours, cells were harvested with $0.05 \%$ trypsin and $0.02 \%$ EDTA in phosphate buffered saline (PBS), and counted. Data are expressed as number of cells.

\section{Cell attachment assay}

The cell attachment assay followed the method described earlier. ${ }^{50}$ To coat the plates with GO and TEA-rGO, a $1 \mathrm{~mL}$ solution of $20 \mu \mathrm{g} / \mathrm{mL}$ in PBS was added in $35 \mathrm{~mm}$ tissue culture plates. Plates were allowed to sit at $37^{\circ} \mathrm{C}$ for 2 hours and then the solution was removed and plates were washed with PBS. To coat the plates with gelatin, a $1 \mathrm{~mL}$ solution of $0.2 \%$ gelatin in PBS was added to $35 \mathrm{~mm}$ tissue culture plates, and coated plates were left at room temperature for 2 hours. Cells were seeded at a density of $1 \times 10^{4}$ cells $/$ well in various coated plates and incubated for 24 hours at $37^{\circ} \mathrm{C}$ in $5 \% \mathrm{CO}_{2}$. After incubation, unattached cells were gently removed with $1 \mathrm{~mL}$ PBS. Attached cells were harvested with trypsin and cells were counted as described above. Cells in uncoated plates were used as negative control. Data are expressed as percentage of attached cells compared to initial cells.

\section{Results and discussion Characterization of GO and TEA-rGO}

Figure 1 shows the conversion of GO to graphene, which is confirmed by the color change from pale yellow to black, following the chemical reduction. Such observation provides a piece of evidence to support the formation of $\mathrm{rGO} .{ }^{51}$ The $\mathrm{UV}$-vis absorption spectra of the $\mathrm{GO}$ and $\mathrm{rGO}$ suspensions are exhibited in Figure 2. After reduction of the GO by TEA, the color of the GO suspension changed from light brown to black. The black color of the rGO indicates removal of oxygen-containing bonds, resulting in electronic conjugation within reduced sheets. ${ }^{52}$ The optical absorption spectra also 
A

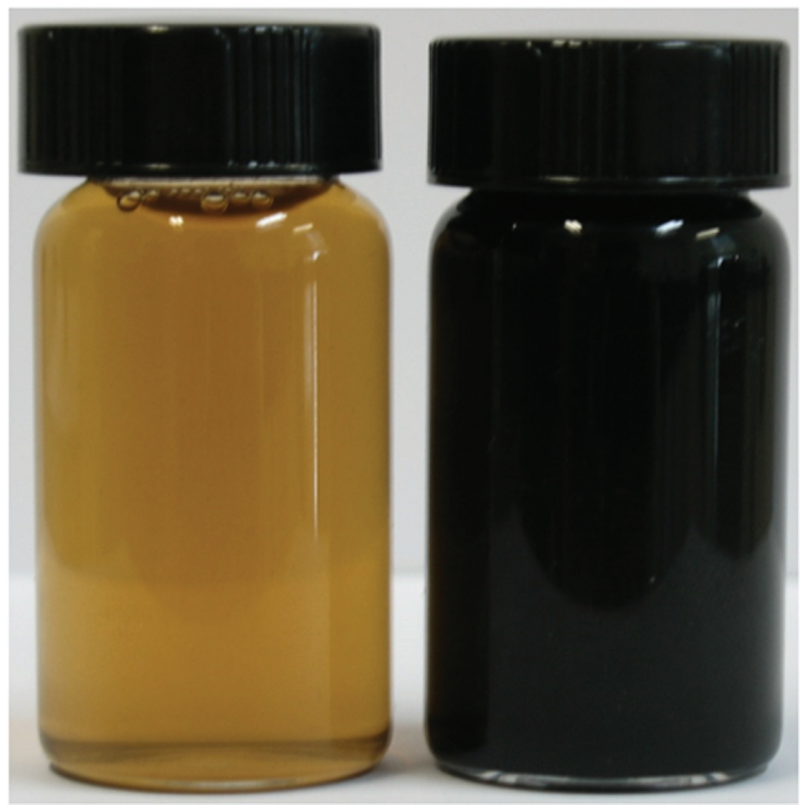

Figure I Digital photographs of aqueous dispersions of GO before and after reduction with TEA.

Notes: Digital photographs of aqueous dispersions $(0.5 \mathrm{mg} / \mathrm{mL})$ of $\mathrm{GO}$ before $(\mathbf{A})$ and after (B) the reduction with TEA, which were kept at $30^{\circ} \mathrm{C}$ for 60 minutes. Abbreviations: GO, graphene oxide; TEA, triethylamine.

show that the absorption peak of the GO suspension is around $231 \mathrm{~nm}$, while the absorption peaks of the reduced suspensions shift into wavelengths of around $260 \mathrm{~nm}$, corresponding to deoxygenation of the GO suspension under the reduction processes. The results confirm the transition of GO to graphene.

\section{X-ray diffraction analysis}

Further characterization of GO and TEA-rGO was carried out by X-ray diffraction. The characterized peak of GO appears at $2 \theta=11.7^{\circ} \mathrm{nm}$, corresponding to a d-spacing

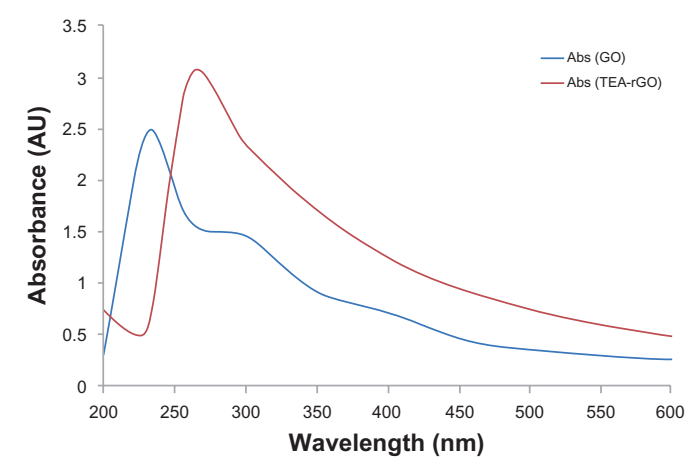

Figure 2 UV-visible absorption spectra of GO and the TEA-rGO suspension in water.

Abbreviations: UV, ultraviolet; GO, graphene oxide; TEA, triethylamine; Abs, absorbance.
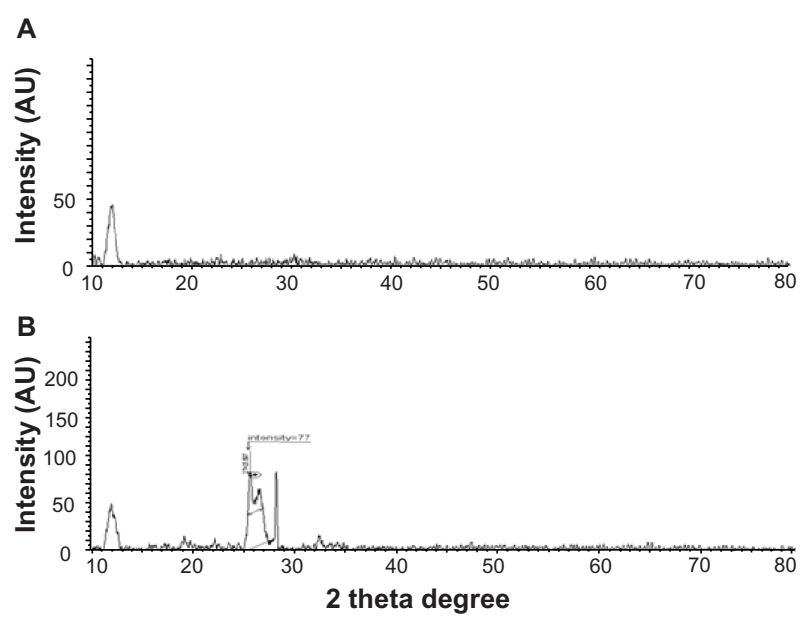

Figure 3 XRD pattern of GO and TEA-rGO.

Notes: X-ray diffraction (A) GO and (B) TEA-rGO.

Abbreviations: XRD, X-ray diffraction; GO, graphene oxide; TEA-rGO, triethylamine-reduced graphene oxide.

of $0.76 \mathrm{~nm}$ (Figure 3A). In contrast to GO, the TEA-rGO shows two peaks; one peak appears at $10.6^{\circ}$, corresponding to d-spacing of $2.1 \mathrm{~nm}$; another broader peak is centered at $25.5^{\circ}$, corresponding to a d-spacing of $0.36 \mathrm{~nm}$ (Figure 3B), which may be a result of some restacked graphene layers. Note that this spacing is very close to pristine graphite, indicating that the functional groups of GO have been efficiently removed. The interlayer spacing decreased to $0.35 \mathrm{~nm}$, which suggests that removal of oxygen and water from the interlayer occurred during exfoliation, at a large rate. This broad peak is also suggestive of a loss of the long range order in graphenes. ${ }^{53}$ Though there is a decrease in the interlayer spacing compared with GO, the basal spacing of rGO is higher than that of well-ordered graphite (single-layer pristine graphene). The higher basal spacing may be due to the presence of residual oxygen functional groups, indicating incomplete reduction of GO. ${ }^{54}$

\section{Size distribution analysis by dynamic light scattering (DLS)}

The DLS method was adopted to measure the size of GO and TEA-rGO in aqueous solution; DLS results could contribute to show the size differences between GO and rGO. As shown in Figure 4A, the results indicate that the hydrodynamic diameter of GO sheets in water is distributed from about $1645 \mathrm{~nm}$ in size. Upon reduction of GO by TEA, the particle size is shifted to an increase in size distribution with a hydrodynamic diameter centered around $2116 \mathrm{~nm}$ (Figure 4B). The rGO particles were formed by reducing GO nanosheets, and their size is slightly larger than that of GO 

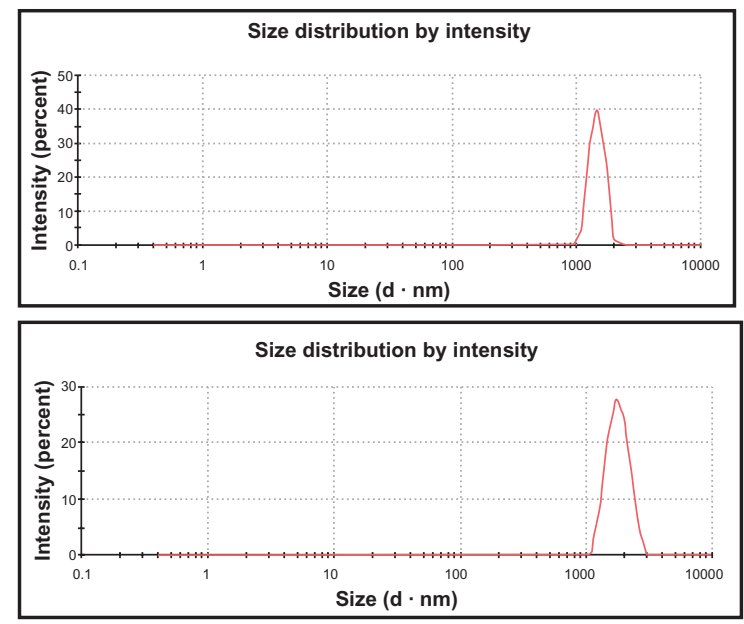

Figure 4 Hydrodynamic size distribution of GO and TEA-rGO.

Notes: Hydrodynamic size distribution of (A) GO and (B) TEA-rGO $(500 \mu \mathrm{g} / \mathrm{mL})$ measured by DLS at room temperature in DI water.

Abbreviations: GO, graphene oxide; TEA-rGO, triethylamine-reduced graphene oxide; DLS, dynamic light scattering; DI, deionized.

particles because of the aggregation of TEA-rGO fragments. This obvious change in size distribution indicates that TEA not only acted as a reducing agent to prepare graphene, but it was also functionalized on the surfaces of the resulting rGO, leading to an increased Brownian motion rate after the reduction process. Wang et $\mathrm{al}^{55}$ observed that after the reduction of GO with heparin, the average size of rGO was larger than GO. Liu et $\mathrm{al}^{56}$ analyzed the size of various graphene based materials; among them GO nanosheets are the smallest in size. Although graphite oxide particles have similar chemical functionality to $\mathrm{GO}$ nanosheets, their average size is nearly 20 times larger than that of GO nanosheets. The rGO particles were formed by reducing $\mathrm{GO}$ nanosheets, and their size is about nine times larger than that of GO nanosheets because of the aggregation of rGO fragments. ${ }^{56}$ In order to further confirm size, the dispersions were further dropped on aluminum foil and dozens of SEM images were taken randomly for each sample.

\section{SEM analysis}

SEM images of GO sheets were smooth with folded shapes at the edges; they also looked like waves (Figure 5A). A thin layer of TEA-rGO sheets displayed a crumpled and wrinkled structure; they look like typical folded paper (Figure 5B). The geometric wrinkling arising from $\pi-\pi$ interaction within sheets of graphene not only minimizes the surface energy but also induces mechanical integrity with tensile strength and good film-forming ability. ${ }^{57}$ In addition, the wrinkled structure of TEA-rGO sheets provides a large rough surface as a scaffold for further modification. Stankovich et a ${ }^{13}$
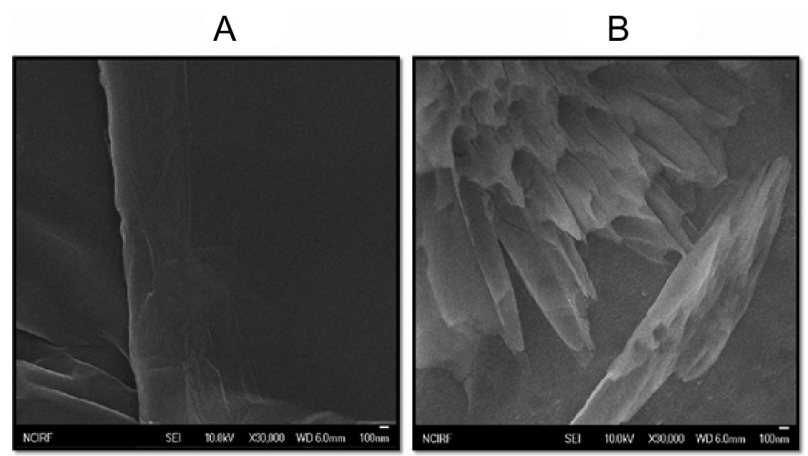

Figure 5 SEM images of GO and TEA-rGO.

Notes: SEM images of (A) GO and (B) TEA-rGO.

Abbreviations: SEM, scanning electron microscopy; GO, graphene oxide; TEA-rGO, triethylamine-reduced graphene oxide.

observed that the reduced GO material consists of randomly aggregated, thin, crumpled sheets closely associated with each other and forming a disordered solid.

\section{Raman spectroscopy}

The Raman spectra further support the structural change before and after the reduction of graphite oxide. ${ }^{58}$ Earlier reports suggested that graphene obtained by the chemical reduction method exhibits two characteristic main peaks: the $\mathrm{D}$ band at $1350 \mathrm{~cm}^{-1}$ and $\mathrm{G}$ band at $1575 \mathrm{~cm}^{-1} .57,58 \mathrm{In}$ our present work, we observed that GO showed a D band at $1395 \mathrm{~cm}^{-1}$ and $\mathrm{G}$ band at $1608 \mathrm{~cm}^{-1}$ respectively (Figure 6A). After reduction of GO, the $\mathrm{rGO}$ showed the corresponding bands of D and $\mathrm{G}$ band appearing at 1347 and $1575 \mathrm{~cm}^{-1}$, respectively (Figure 6B). The G band of TEA-rGO red-shifted from $1603 \mathrm{~cm}^{-1}$ to $1575 \mathrm{~cm}^{-1}$, which was recognized as recovery of the hexagonal network of the carbon atom. The intensity ratio of the $\mathrm{D}$ and $\mathrm{G}$ band (ID/IG) revealed structural defects and the indication of disorder. After reduction, the ID/ IG ratio increased from 1.7 to 2.94 in TEA-rGO. Compared with the GO, the intensity ratio of TEA-rGO was high, which indicates high level defects. This change suggests that more SP2 domains are formed during the reduction of graphite oxide, which agrees very well with other reports. . 14,59,60 $^{2}$

In order to see the quality of synthesized graphene, we used Raman spectroscopy, which is the potential candidate for nondestructive and quick inspection of multiple layers of graphene. Raman spectra of graphene-based materials showed a 2D band which was sensitive to stacking of graphene sheets. 2D Raman band shape and position are good fingerprints of single and bilayer graphene to distinguish them from the multilayer. We observed a significant feature and intensity of 2D bands 2670 located between $2600-3000 \mathrm{~cm}^{-1}$ in the Raman spectrum. As shown in Figure 6B, the 2D band 
A

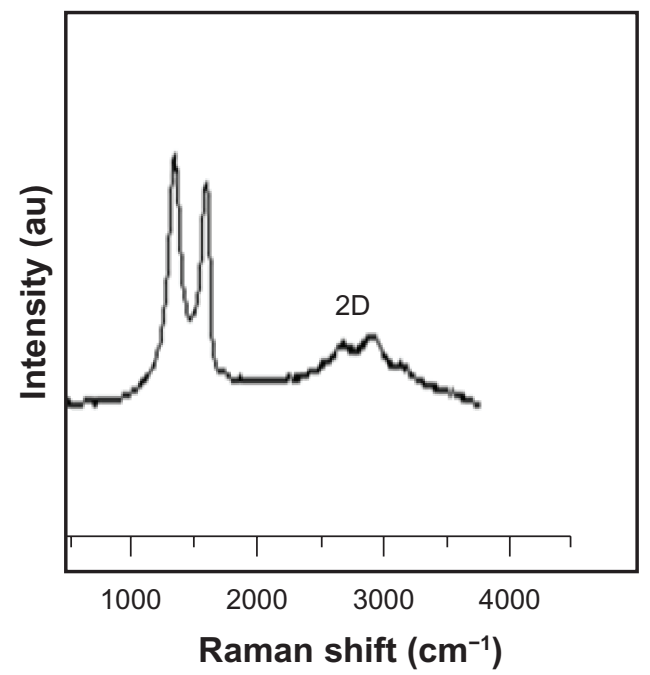

B

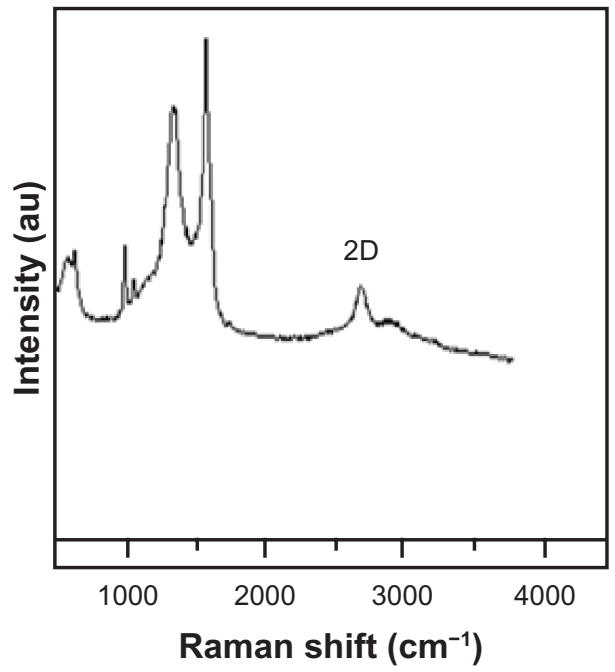

Figure 6 Raman spectra of GO and TEA-rGO.

Notes: Raman spectra of (A) GO and (B) TEA-rGO.

Abbreviations: GO, graphene oxide; TEA-rGO, triethylamine-reduced graphene oxide; 2D, 2-dimensional; au, absorbance units.

of TEA-rGO centered about $2670 \mathrm{~cm}^{-1}$ with a low-intensity shoulder at the higher wave numbers, and we analyzed the peak intensity between $2 \mathrm{D}$ and $\mathrm{G}$ bands, the ratio of which is 2.2. The results suggest that the synthesized graphene could be a monolayer. ${ }^{13,49}$

\section{Atomic force microscopy (AFM) analysis}

We used an atomic force microscope to probe film morphology and thickness. AFM images confirm that evaporated dispersions of GO and graphene are comprised of isolated graphitic sheets. GO has lateral dimensions of several micrometers and a thickness of $1 \mathrm{~nm}$, which is characteristic of a fully exfoliated GO sheet. ${ }^{13}$ We have shown a typical AFM image of GO and rGO dispersion in water after their deposition on a freshly cleaved mica surface through drop casting method. We observed that the film morphology changes significantly with this dimension. Figure 7A and $\mathrm{C}$ are representative of the topology of films from GO and TEA-rGO solutions with concentrations in the $1 \mathrm{mg} / \mathrm{mL}$ range. GO and TEA-rGO sheets with the lateral size up to $5 \mu \mathrm{m}$ were observed as shown in Figure 7A and C. As the prepared $\mathrm{GO}$ and $\mathrm{rGO}$ dispersion shows, the height profile of the AFM image is about $1.06 \mathrm{~nm}$ and $1.02 \mathrm{~nm}$ (Figure 7B and D), respectively. Compared with GO sheets, the rGO is less thick. We observed increased disorder and roughness and the appearance of micrometer-long wrinkles; it became increasingly hard to identify the edges of the separate sheets. Wrinkles on graphene's surface, dried on the mica substrate, decreased its apparent thickness $(1.02 \mathrm{~nm})$ as measured by
AFM (Figure 7D). The decrease in the lateral dimensions of graphene sheets is also attributed to excessive sonication during each step of the preparation of graphene.

\section{Effect of GO and TEA-rGO on cell viability}

The evaluation of biocompatibility of graphene materials is an important factor in biological and biomedical applications, including drug delivery and gene transfection. It has been found that WST-8 is an appropriate assay for cell viability and proliferation tests of graphene materials. ${ }^{36}$ As shown in Figure 8, GO shows a dose-dependent significant toxicity in PMEFs cells $(P<0.05)$; however the lower concentration of $20 \mu \mathrm{g} / \mathrm{mL}$ displayed neither toxic nor stimulatory effect, whereas TEA-rGO didn't show an obvious decrease in cell viability up to the concentrations of $100 \mu \mathrm{g} / \mathrm{mL}$, which suggests that functionalization of GO by TEA plays an important role in cell biocompatibility. Interestingly, the lower concentration of TEA-rGO $(20 \mu \mathrm{g} / \mathrm{mL})$ shows a significant stimulatory effect when compared to control $(P<0.05)$. Schrand et $\mathrm{al}^{61}$ examined biocompatibility of various carbon nanomaterials such as nanodiamonds (NDs), single- and multi-walled carbon nanotubes (SWNTs, MWNTs), and carbon black (CB), at concentrations ranging from 25-100 $\mu \mathrm{g}$ / $\mathrm{mL}$ for 24 hours in neuronal and lung cell lines; the results indicated that these carbon nanomaterials displayed differential biocompatibility in these two different cell lines; however, the greatest biocompatibility was found after incubation with NDs and both cell types. Gelatin functionalized graphene 


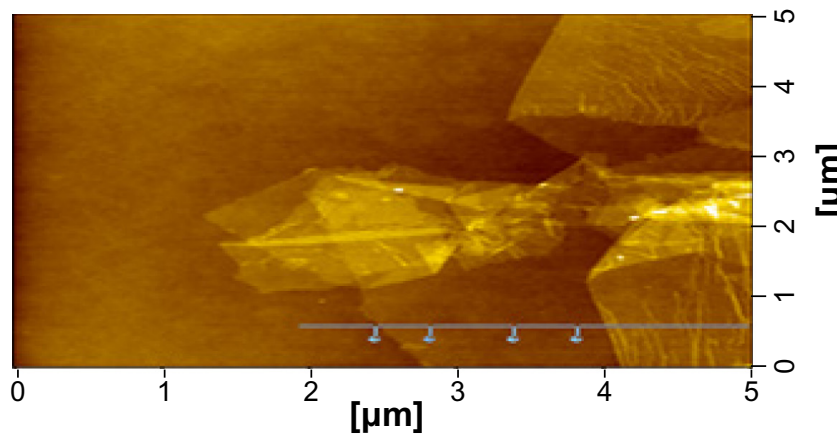

A

\begin{tabular}{|r|r|r|r|r|r|}
\hline & Z1 [nm] & Z2 [nm] & \multicolumn{1}{c|}{$\Delta$ Z [nm] } & Distance [nm] & \multicolumn{1}{c|}{$\phi^{\circ}$} \\
\hline & 2.63 & 3.69 & 1.06 & 375.00 & 0.2 \\
\hline & 2.74 & 2.53 & 0.20 & 922.62 & 0.0 \\
\hline & 2.53 & 2.30 & 0.23 & 446.43 & 0.0 \\
\hline & & & & & \\
\hline & & & & & \\
\hline
\end{tabular}

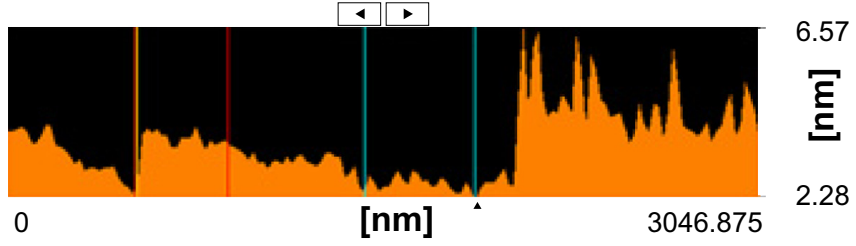

B
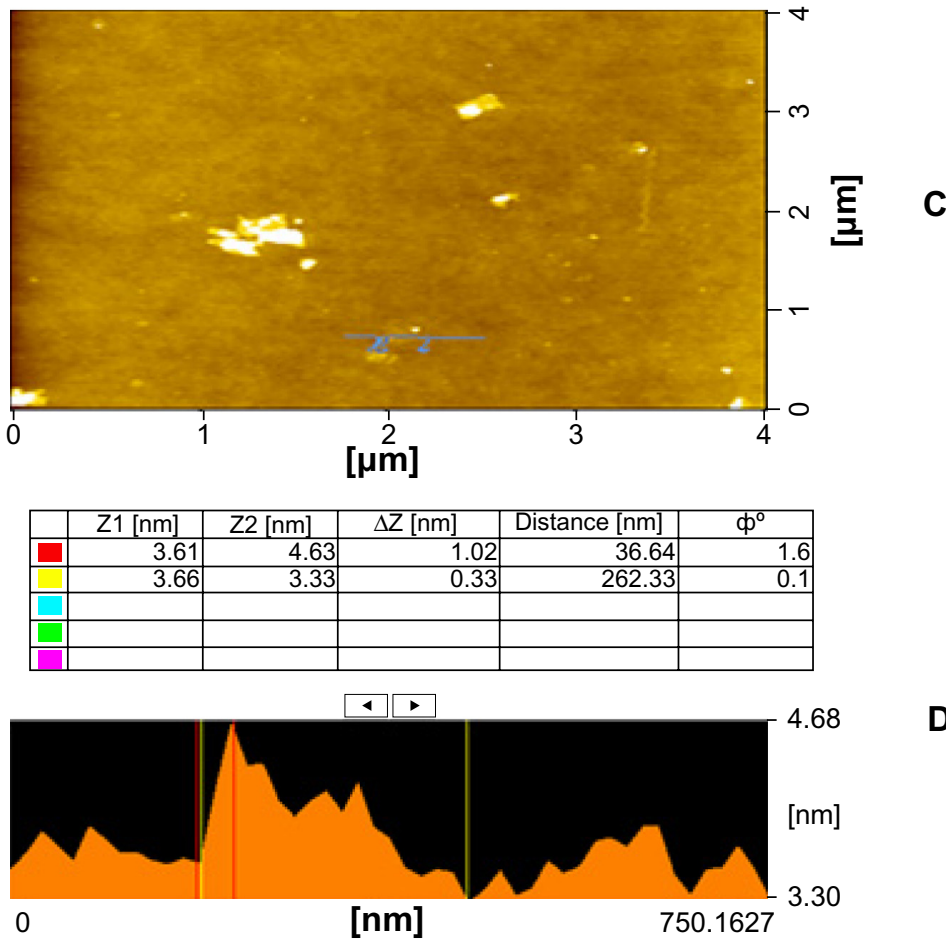

D

Figure 7 AFM images and height profiles of GO and TEA-rGO.

Notes: (A) AFM images and (B) height profile of GO; (C) AFM images and (D) height profile of TEA-rGO.

Abbreviations: AFM, atomic force microscopy; GO, graphene oxide; TEA-rGO, triethylamine-reduced graphene oxide.

nanosheets shows nontoxicity in MCF-7 cells, even at a high concentration of $200 \mu \mathrm{g} / \mathrm{mL}$. Mejías Carpio et $\mathrm{al}^{62}$ investigated the toxicity of polyvinyl-N-carbazole (PVK)-graphene oxide (GO) with planktonic microbial cells, biofilms, and NIH 3T3 fibroblast cells, and the results suggested that the PVK-GO nanocomposite presents higher antimicrobial effects than the pristine GO; however, the same nanocomposite didn't induce significant cytotoxicity in fibroblast cells. The cells exposed to the suspension of GO and functioning with polyethylene glycol (PEG) in the $\mathrm{rGO} / \mathrm{PEG}$ concentration range between $3.125 \mu \mathrm{g} / \mathrm{mL}$ and $25 \mu \mathrm{g} / \mathrm{mL}$ show relatively high viability in mouse fibroblast cells. ${ }^{63}$ Chen et al ${ }^{64}$ reported that graphene 


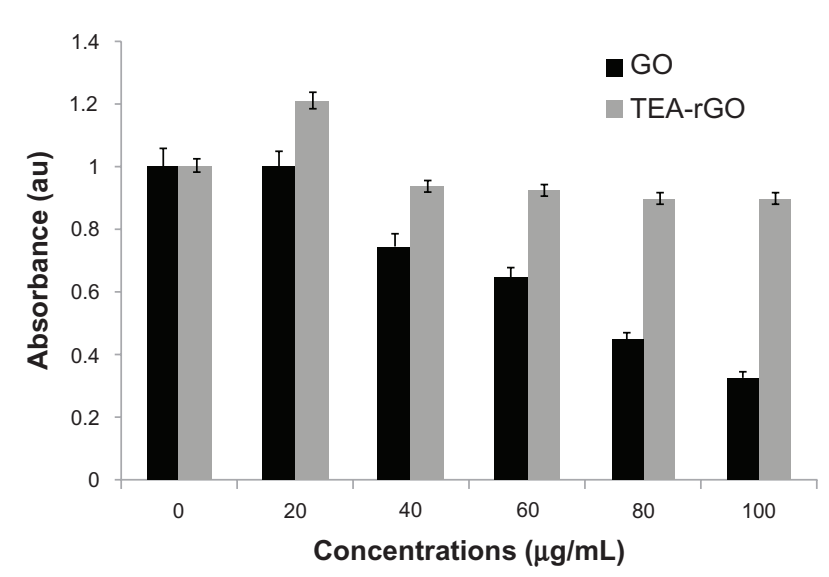

Figure 8 Effect of GO and TEA-rGO on cell viability of PMEFs cells.

Notes: Cell viability of PMEFs cells was determined using WST-8 assay after 24 hours exposure to different concentrations of GO or TEA-rGO. The results represent the means of three separate experiments, and error bars represent the standard error of the mean. GO treated groups showed statistically significant differences from the control group by the Student's $t$-test $(P<0.05)$.

Abbreviations: GO, graphene oxide; TEA-rGO, triethylamine-reduced graphene oxide; PMEFs, primary mouse embryonic fibroblast cells; au, absorbance units; WST, water-soluble tetrazolium salt.

and GO can support mouse induced pluripotent stem cell (iPSC) culture and allow for spontaneous differentiation. Another report suggests that GO is a great support for mammalian cell attachment, growth, and proliferation. ${ }^{65}$

\section{Impact of GO and TEA-rGO on membrane integrity}

LDH is a soluble cytosolic enzyme which when released into the extracellular medium (due to membrane damage) consequently leads to apoptosis. It is widely accepted as an indicator of lytic cell death. LDH release measures the membrane damage, a hallmark of necrosis. To further support the biocompatibility of TEA-rGO in PMEFs cells, the cells were treated with various concentrations of GO and TEArGO for 24 hours and extracellular LDH activity was then measured. The results suggest that cell membrane integrity in PMEFs cells was compromised by GO and increasing the concentration of the GO leads to a higher amount of leakage in the LDH assay; this indicates the membrane integrity was compromised and cellular contents were found in the media, and in turn suggests that GO induces significant toxicity $(P<0.05)$ when compared to untreated cases. Interestingly TEA-rGO shows no effects on membrane damage up to $100 \mu \mathrm{g} / \mathrm{mL}$ (Figure 9). LDH activity was slightly decreased when compared to control. Similar to our results, Chang et $\mathrm{al}^{35}$ observed that the LDH levels of GO-treated cells are even slightly lower than that of the control cells. Park et $\mathrm{al}^{66}$ demonstrated that nitrogen doped graphitic hollow spheres had little effect on cell proliferation/viability

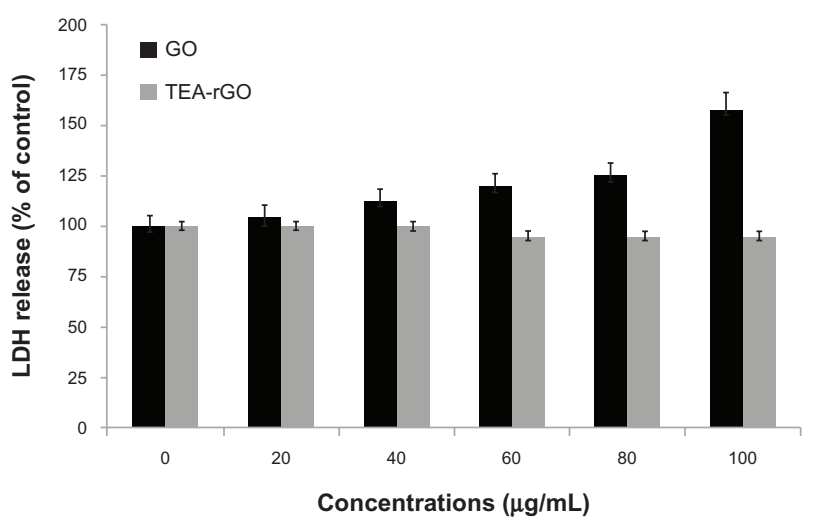

Figure 9 Effect of GO and TEA-rGO on LDH activity in PMEFs cells.

Notes: LDH activity was measured by changes in optical densities due to NAD+ reduction, monitored at $490 \mathrm{~nm}$, as described in Materials and methods, using the Cytotoxicity Detection Lactate Dehydrogenase kit. The results represent the means of three separate experiments, and error bars represent the standard error of the mean. GO treated groups showed statistically significant differences from the control group by the Student's t-test $(P<0.05)$.

Abbreviations: GO, graphene oxide; TEA-rGO, triethylamine-reduced graphene oxide; $\mathrm{LDH}$, lactate dehydrogenase; PMEFs, primary mouse embryonic fibroblast cells; $\mathrm{NAD}^{+}$, nicotinamide adenine dinucleotide.

and LDH release compared to graphitic hollow spheres, suggesting that nitrogen-doping could reduce cytotoxicity of graphitic hollow spheres. The data obtained revealed that PMEFs cells had significant biocompatibility with TEA-rGO treatment. These results clearly suggest that TEA-rGO exhibited no toxicity, implying its great potential for biological and pharmaceutical applications.

\section{The effect of lower concentrations of TEA-rGO on proliferation of cells}

Biocompatibility is an important factor for the development of any new nanomaterials in biological and biomedical applications. Surprisingly, cell viability assays suggest that TEA-rGO had a stimulatory effect on PMEFs at a concentration of $20 \mu \mathrm{g} / \mathrm{mL}$. Furthermore, we were interested in evaluating whether or not lower concentrations of GO and TEA-rGO promote proliferation; we therefore selected various concentrations between 5 and $20 \mu \mathrm{g} / \mathrm{mL}$ for both $\mathrm{GO}$ and TEA-rGO, and the cells were seeded $1 \times 10^{4}$ at the same density in all plates. After 24 hours of incubation, we measured the number of cells after culturing in the medium containing various concentrations of GO and TEA-rGO (from 5-20 $\mu \mathrm{g} / \mathrm{mL}$ ) on cells treated with GO and TEA-rGO. First, the effect of GO and TEA-rGO on PMEFs' proliferation was assessed by cell population growth assay. Quantitative data suggest that TEA-rGO significantly increased proliferation of PMEFs when compared to negative controls and $\mathrm{GO}$, in a concentration-dependent manner in TEA-rGO treated groups (Figure 10A). Furthermore, microscopic 


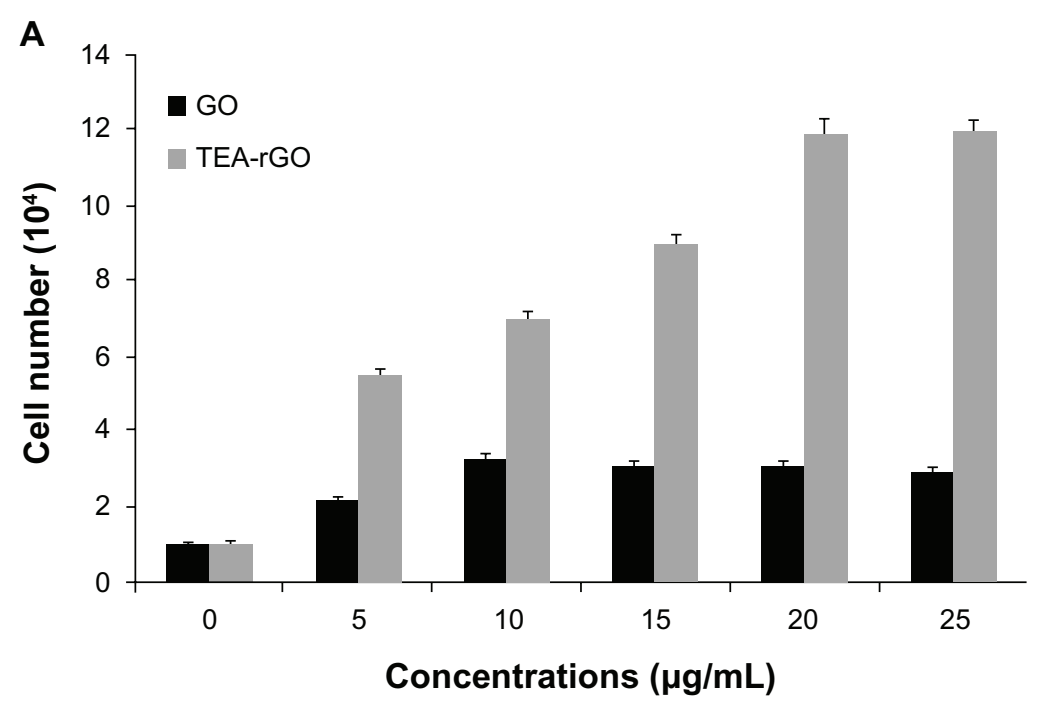

B

\section{Concentrations $(\mu \mathrm{g} / \mathrm{mL})$}

0

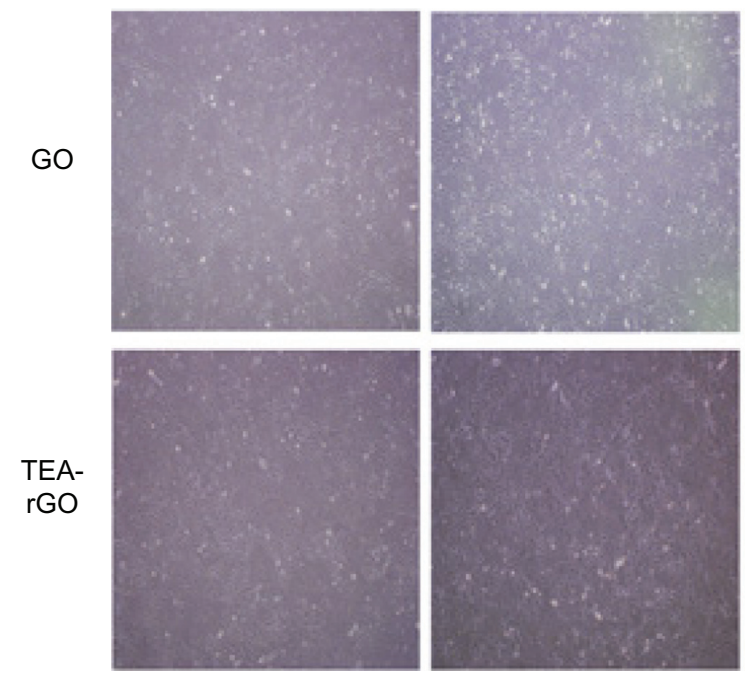

25
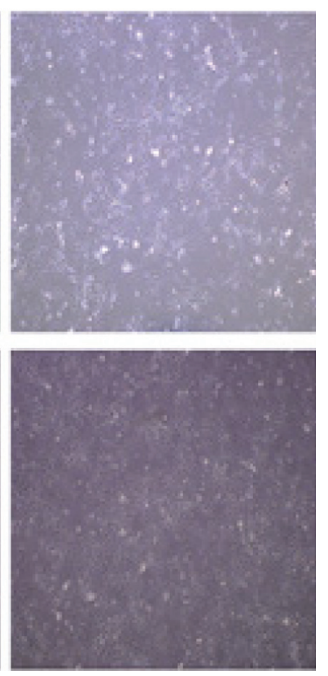

Figure 10 The effect of lower concentration of TEA-rGO on proliferation of PMEFs cells.

Notes: (A) PMEFs cells were treated with various concentrations of GO and TEA-rGO for 24 hours, cells were harvested with $0.05 \%$ trypsin and $0.02 \%$ EDTA in PBS, and counted. Data are expressed as number of cells. The results represent the means of three separate experiments and error bars represent the standard error of the mean. GO and TEA-rGO treated groups showed statistically significant differences from the control group by the Student's $t$-test $(P<0.05)$. (B) Representative microscopic images of GO and TEA-rGO treated cells ( 0.5 and $25 \mu \mathrm{g} / \mathrm{mL})$.

Abbreviations: GO, graphene oxide; TEA-rGO, triethylamine-reduced graphene oxide; EDTA, ethylenediaminetetraacetic acid; PBS, phosphate buffered saline; PMEFs, primary mouse embryonic fibroblast cells.

images show the evidence for proliferation in two different concentrations (Figure 10B). When compared to control and GO, the TEA-rGO treated plates show stronger effect, and the cells were crowded and forming networks due to overgrowth of cells, which indicates that the functionalization of the rGO could contribute to the proliferation of the cells. The biopolymer functionalized rGO exhibits an ultralow hemolysis ratio and good cytocompatibility in human umbilical vein endothelial cells (HUVECs), even at a high concentration of $100 \mu \mathrm{g} / \mathrm{mL} \cdot{ }^{67}$ Liu et al ${ }^{39}$ developed a glucose oxidase-immobilized GO electrode which shows reproducibility and good storage stability, as well as significant biocompatibility with retinal pigment epithelium (RPE) cells. Li et $\mathrm{al}^{68}$ studied the cytotoxicity of the graphene oxide (GO)-hydroxyapatite (HA) and chitosan (CS)-GO-HA nanocomposites in the murine fibroblast L-929 cell line and the human osteoblast-like MG-63 cell line, and suggested that the novel synthesized GO-HA and CS-GO-HA nanocomposites induced no obvious inhibitory effects on the in vitro cell proliferation rate of L-929 and MG-63 cells; 
they exhibited excellent in vitro cytocompatibility within a concentration of $100 \mu \mathrm{g} / \mathrm{mL}$, especially for CS-GO-HA.

\section{TEA-rGO enhances the attachment of PMEFs cells}

Graphene has been employed as a substrate to be interfaced with various biomolecules and cells. Biological modification in turn benefits graphene by improving its biocompatibility, solubility, and selectivity. ${ }^{34}$ The cell viability results suggest that TEA-rGO shows significantly better biocompatibility than GO. Therefore, because we were further interested in evaluating whether TEA-rGO-coated substrates can promote the attachment of cells when compared to uncoated plates, we selected a particular dose $(5 \mu \mathrm{g} / \mathrm{mL})$ which is the lowest concentration for GO and TEA-rGO respectively. The typical positive control (gelatin) was also used as a benchmark for the attachment assay. The cells were seeded $1 \times 10^{4}$ at the same density in all the plates. The cells were allowed to attach and develop on the substrates. The cells were treated with the same concentration of GO and TEA-rGO for 24 hours. Quantitative analysis was carried out to determine the number of attached cells on each substrate for 24 hours of incubation (Figure 11A). The microscopic images indicate that the cell densities on the dish without coating and the GO-coated dish were lower than that on the TEA-GO coated surface, which indicates more efficient cell adherence onto TEA-rGO than the control and GO surfaces (Figure 11B). Although GO promoted the attachment of cells, the effect was significant $(P<0.05)$ in TEA-rGO coated plates, which could be the reason for functionalization of GO by TEA. Chen et $\mathrm{al}^{65}$ reported that graphene and GO can support mouse iPSCs culture and allow for spontaneous differentiation. Graphene and CNTs supported behavior of NIH-3T3 fibroblast cells in response to proliferation, cell shape, focal adhesion, and cell adhesion-related gene expression levels; gene transfection efficiency of cells grown on the substrates was improved up to $250 \%$ compared to that of cells grown on a cover glass. ${ }^{69}$ The results suggest that TEA-rGO could provide a wider surface for cell adhesion. These results clearly indicated that TEArGO did not induce any cytotoxic effects on the cells, but that it promoted cell attachment. Ruiz et a ${ }^{65}$ demonstrated that mammalian colorectal adenocarcinoma HT-29 cells attached more efficiently in $10 \mu \mathrm{g} / \mathrm{mL}$ of GO than noncoated dishes. Pretreating rats with amine-modified SWNTs can protect neurons and enhance the recovery of behavioral functions in rats with induced stroke. ${ }^{70}$ Previous findings suggested that positively charged modifications such as amine $\left(2 \mathrm{NH}^{2}\right)$ groups can stimulate neurite outgrowth. ${ }^{71}$ Plasma treatment

\section{A}

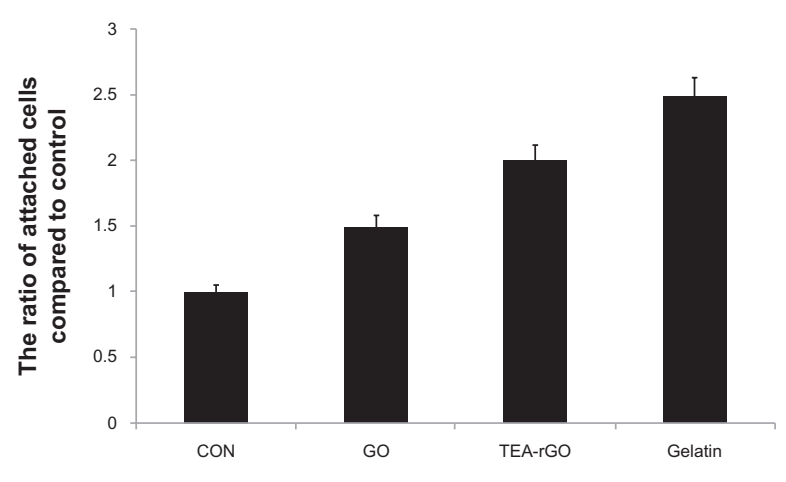

B
CON

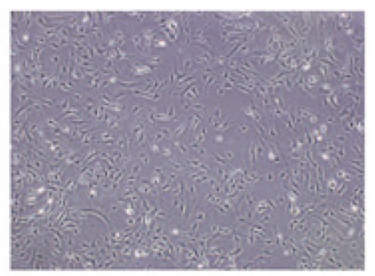

TEA-rGO

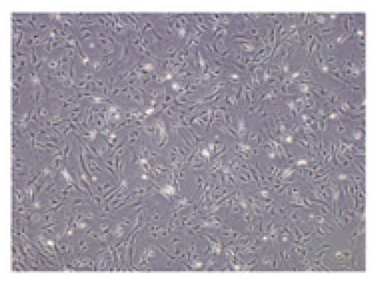

$\mathrm{GO}$

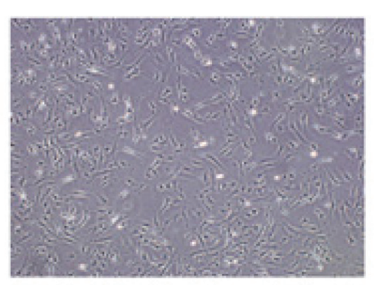

Gelatin

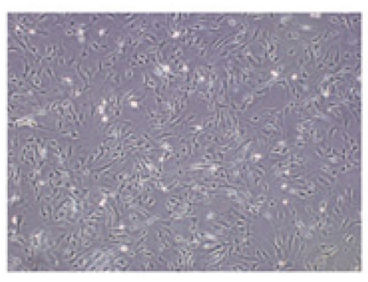

Figure II Effect of GO and TEA-rGO on attachment of PMEFs cells.

Notes: (A) The cells were grown in coated dishes for 24 hours. The numbers of cells attached to coated dishes were counted after 24 hours. Triplicate cell counts were performed in each experiment, and the experiment was repeated three times. The results represent the means of three separate experiments and error bars represent the standard error of the mean. GO and TEA-rGO $(5 \mu \mathrm{g} / \mathrm{mL})$ treated groups showed statistically significant differences from the control group by the Student's $t$-test $(P<0.05)$. Data are expressed as percentage of attached cells compared to initial cells. (B) Representative microscopic images of GO and TEArGO treated cells.

Abbreviations: GO, graphene oxide; TEA-rGO, triethylamine-reduced graphene oxide; PMEFs, primary mouse embryonic fibroblast cells; CON, control.

may have increased surface defects on the nanotubes, resulting in greater surface energy and polarity, which favor the growth of neural tissue. ${ }^{72}$

Our recent studies demonstrated that graphene nanomaterials play an extremely important role in toxicity. Bacterially-reduced graphene oxide (B-rGO) induces cytotoxic effects on human breast cancer cell lines, and these effects are concentration-dependent. ${ }^{73}$ In contrast, we also demonstrated that the biocompatibility of microbially rGO (M-rGO) in PMEFs cells. ${ }^{28}$ Altogether, our findings and those of other research groups suggest that the biocompatibility of 
graphene is dependent on the physicochemical properties of graphene-based materials, including density of functional groups, size, conductivity, the type of reducing agents used for the deoxygenation of GO, the degree of functionalization, and the cell types.

\section{Conclusion}

We presented a simple, nontoxic and room temperature mediated synthesis of water-soluble graphene. We used TEA as a reducing and stabilizing agent for effective preparation of well-stable and highly soluble graphene. The prepared graphene was characterized using various analytical techniques and was evaluated for cytotoxicity. Cell viability assays exhibited GO-caused dose-dependent toxicity, whereas TEA-rGO displayed significant biocompatibility with PMEFs cells. The lower concentration of GO and TEA-rGO enhances proliferation and cell attachment. Our present findings provide a cost effective and environmentally-friendly approach to the production of stable aqueous dispersions of rGO; this approach is amenable to bulk production. To the best of our knowledge, this is the first such example for TEA reduced GO. Graphene could be a significant biocompatible scaffold substrate for stem cells due to its cost effectiveness, easy availability, solubility, and the high quality of continuous graphene sheets, producible on a large scale.

\section{Acknowledgments}

This paper was supported by the SMART-Research Professor Program of Konkuk University. Dr Sangiliyandi Gurunathan was supported by a Konkuk University SMART-Full time Professorship. This work was supported by the Woo Jang-Choon project (PJ007849) and the next generation of Biogreen 21 (PJ009107) from the Rural Development Administration (RDA), Republic of Korea.

\section{Disclosure}

The authors report no conflicts of interest in this work.

\section{References}

1. Novoselov KS, Geim AK, Morozov SV, et al. Electric field effect in atomically thin carbon films. Science. 2004;306(5696):666-669.

2. Geim AK, Novoselov KS. The rise of graphene. Nat Mater. 2007;6(3): 183-191.

3. Rao CN, Sood AK, Subrahmanyam KS, Govindaraj A. Graphene: the new two-dimensional nanomaterial. Angew Chem Int Ed Engl. 2009;48(42): 7752-7777.

4. Dikin DA, Stankovich S, Zimney EJ, et al. Preparation and characterization of graphene oxide paper. Nature. 2007;448(7152):457-460.

5. Dreyer DR, Park S, Bielawski C, Ruoff RS. The chemistry of graphene oxide. Chem Soc Rev. 2009;39(1):228-240.

6. Berger C, Song Z, Li X, et al. Electronic confinement and coherence in patterned epitaxial graphene. Science. 2006;312(5777):1191-1196.
7. Kim KS, Zhao Y, Jang H, et al. Large-scale pattern growth of graphene films for stretchable transparent electrodes. Nature. 2009;457(7230): 706-710.

8. Li D, Müller MB, Gilje S, Kaner RB, Wallace GG. Processable aqueous dispersions of graphene nanosheets. Nat Nanotechnol. 2008;3(2): 101-105.

9. Wang Z, Zhou X, Zhang J, Boey F, Zhang H. Direct Electrochemical Reduction of Single-Layer Graphene Oxide and Subsequent Functionalization with Glucose Oxidase. J Phys Chem C. 2009;113(32): 14071-14075.

10. Hummers WS, Offeman RE. Preparation of Graphitic Oxide. $J$ Am Chem Soc. 1958;80(6):1339.

11. Xu Y, Bai H, Lu G, Li C, Shi G. Flexible graphene films via the filtration of water-soluble noncovalent functionalized graphene sheets. $J \mathrm{Am}$ Chem Soc. 2008;130(18):5856-5857.

12. Pham TA, Kim JS, Kim JS, Jeong YT. One-step reduction of graphene oxide with L-glutathione. Colloids Surf A. 2011;384(1-3):543-548.

13. Stankovich S, Piner RD, Chen X, Wu N, Nguyen ST, Ruoff RS. Stable aqueous dispersions of graphitic nanoplatelets via the reduction of exfoliated graphite oxide in the presence of poly(sodium 4-styrenesulfonate). J Mater Chem. 2006;16:155-158.

14. Stankovich S, Dikin DA, Dommett GH, et al. Graphene-based composite materials. Nature. 2006;442(7100):282-286.

15. Tung VC, Allen MJ, Yang Y, Kaner RB. High-throughput solution processing of large-scale graphene. Nature Nanotech. 2009;4(1):25-29.

16. Higginbotham AL, Kosynkin DV, Sinitskii A, Sun Z, Tour JM. Lowerdefect graphene oxide nanoribbons from multiwalled carbon nanotubes. ACS Nano. 2010;4(4):2059-2069.

17. Zhou X, Liu Z. A scalable, solution-phase processing route to graphene oxide and graphene ultra large sheets. Chem Commun (Camb). 2010;46(15):2611-2613.

18. Salas EC, Sun Z, Lüttge A, Tour JM. Reduction of graphene oxide via bacterial respiration. ACS Nano. 2010;4(8):4852-4853.

19. Min K, Han TH, Kim J, et al. A facile route to fabricate stable reduced graphene oxide dispersions in various media and their transparent conductive thin films. J Colloid Interface Sci. 2012;383(1):36-42.

20. Fan X, Peng W, Li Y, et al. Deoxygenation of exfoliated graphite oxide under alkaline conditions: a green route to graphene preparation. $A d v$ Mater. 2008;20(23):4490-4493.

21. Tang LA, Lee WC, Shi H, et al. Highly wrinkled cross-linked graphene oxide membranes for biological and charge-storage applications. Small. 2012;8(3):423-431.

22. Zhang J, Yang H, Shen G, Cheng P, Zhang J, Guo S. Reduction of graphene oxide via L-ascorbic acid. Chem Commun (Camb). 2010;46(7): 1112-1114.

23. Zhu C, Guo S, Fang Y, Dong S. Reducing sugar: new functional molecules for the green synthesis of graphene nanosheets. ACS Nano. 2010;4(4):2429-2437.

24. Khanra P, Kuila T, Kim NH, Bae SH, Yu DS, Lee JH. Simultaneous bio-functionalization and reduction of graphene oxide by baker's yeast. Chem Eng J. 2012;183:526-533.

25. Liu JH, Anilkumar P, Cao L, et al. Cytotoxicity evaluations of fluorescent carbon nanoparticles. Nano Life. 2010;1(1\&2):153-161.

26. Kim JE, Han TH, Lee SH, et al. Graphene Oxide Liquid Crystals. Angew Chem Int Ed. 2011;50(13):3043-3047.

27. Gurunathan S, Han JW, Dayem AA, Eppakayala V, Kim JH. Oxidative stress-mediated antibacterial activity of graphene oxide and reduced graphene oxide in Pseudomonas aeruginosa. Int J Nanomedicine. 2012;7:5901-5914.

28. Gurunathan S, Han JW, Eppakayala V, Kim JH. Microbial reduction of graphene oxide by Escherichia coli: a green chemistry approach. Colloids Surf B Biointerfaces. 2013;102:772-777.

29. Gurunathan S, Han JW, Eppakayala V, Kim JH. An Environmentally Friendly Approach to the Reduction of Graphene Oxide by Escherichia fergusoni. J Nanosci Nanotechnol. 2013;13(3):2091-2098.

30. Hu W, Peng C, Luo W, et al. Graphene-based antibacterial paper. ACS Nano. 2010;4(7):4317-4323. 
31. Akhavan O, Ghaderi E. Toxicity of graphene and graphene oxide nanowalls against bacteria. ACS Nano. 2010;4(10):5731-5736.

32. Akhavan O, Ghaderi E, Rahimi K. Adverse effects of graphene incorporated in $\mathrm{TiO}_{2}$ photocatalyst on minuscule animals under solar light irradiation. J Mater Chem. 2012;22:23260-23266.

33. Zhang Y, Ali SF, Dervishi E, et al. Cytotoxicity effects of graphene and single-wall carbon nanotubes in neural phaeochromocytoma-derived PC12 cells. ACS Nano. 2010;4(6):3181-3186.

34. Wang K, Ruan J, Song H, et al. Biocompatibility of Graphene Oxide. Nanoscale Res Lett. 2011;6(1):8.

35. Chang Y, Yang ST, Liu JH, et al. In vitro toxicity evaluation of graphene oxide on A549 cells. Toxicol Lett. 2011;200(3):201-210.

36. Liao KH, Lin YS, Macosko CW, Haynes CL. Cytotoxicity of graphene oxide and graphene in human erythrocytes and skin fibroblasts. ACS Appl Mater Interfaces. 2011;3(7):2607-2615.

37. Akhavan O, Ghaderi E, Emamy H, Akhavan F. Genotoxicity of graphene nanoribbons in human mesenchymal stem cells. Carbon. 2013;54: 419-431.

38. Yan X, Chen J, Yang J, Xue Q, Miele P. Fabrication of free-standing, electrochemically active, and biocompatible graphene oxide-polyaniline and graphene-polyaniline hybrid papers. ACS Appl Mater Interfaces. 2010;2(9):2521-2529.

39. Liu Y, Yu D, Zeng C, Miao Z, Dai L. Biocompatible Graphene OxideBased Glucose Biosensors. Langmuir. 2010;26(9):6158-6160.

40. Li N, Xia T, Nel AE. The role of oxidative stress in ambient particulate matter-induced lung diseases and its implications in the toxicity of engineered nanoparticles. Free Radic Biol Med. 2008;44(9):1689-1699.

41. Park S, Ruoff RS. Chemical methods for the production of graphenes. Nat Nanotechnol. 2010;4(4):217-224.

42. Agarwal S, Zhou X, Ye F, et al. Interfacing live cells with nanocarbon substrates. Langmuir. 2010;26(4):2244-2247.

43. Robinson JT, Tabakman SM, Liang YY, Wang HL, Casalongue HS, Vinh D. Ultrasmall reduced graphene oxide with high near-infrared absorbance for photothermal therapy. J Am Chem Soc. 2011;133(17) $6825-6831$.

44. Yang K, Zhang SA, Zhang GX, Sun XM, Lee ST, Liu ZA. Graphene in mice: ultrahigh in vivo tumor uptake and efficient photothermal therapy. Nano Lett. 2010;10(9):3318-3323.

45. Chen H, Müller MB, Gilmore KJ, Wallace GG, Li D. Mechanically Strong, Electrically Conductive, and Biocompatible Graphene Paper. Advanced Materials. 2008;20(18):3557-3561.

46. Park S, Mohanty N, Suk JW, et al. Biocompatible, robust free-standing paper composed of a TWEEN/graphene composite. Adv Mater. 2010;22(15):1736-17405.

47. Sasidharan A, Panchakarla LS, Sadanandan AR, et al. Hemocompatibility and macrophage response of pristine and functionalized graphene. Small. 2012;8(8):1251-1263.

48. Singh KS, Singh MK, Kulkarni PP, Sonkar KV, Grácio JJ, Dash D. Amine-modified graphene: thrombo-protective safer alternative to graphene oxide for biomedical applications. ACS Nano. 2012;6(3): 2731-2740.

49. Esfandiar A, Akhavan O, Irajizad A. Melatonin as a powerful bioantioxidant for reduction of graphene oxide. J Mater Chem. 2011;21: 10907-10914.

50. Jiang SY, Shu R, Song ZC, Xie YF. Effects of enamel matrix proteins on proliferation, differentiation and attachment of human alveolar osteoblasts. Cell Prolif. 2011;44(4):372-379.

51. McAllister MJ, Li JL, Adamson DH, et al. Single sheet functionalized graphene by oxidation and thermal expansion of graphite. Chem Mater. 2007;19(18):4396-4404.

52. Kaniyoor A, Baby TT, Ramaprabhu S. Graphene synthesis via hydrogen induced low temperature exfoliation of graphite oxide. J Mater Chem. 2010;20:8467-8469
53. Li D, Müller MB, Gilje S, Kaner RB, Wallace GG. Processable aqueous dispersions of graphene nanosheets. Nat Nanotechnol. 2008;3(2): 101-105.

54. Nethrvathi C, Rajamathi M. Chemically modified graphene sheets produced by the solvothermal reduction of colloidal dispersions of graphite oxide. Carbon. 2008;46(14):1994-1998.

55. Wang Y, Zhang P, Liu CF, Zhan L, Li YF, Huang CZ. Green and easy synthesis of biocompatible graphene for use as an anticoagulant. RSC Adv. 2012;2:2322-2328.

56. Liu S, Zeng TH, Hofmann M, et al. Antibacterial activity of graphite, graphite oxide, graphene oxide, and reduced graphene oxide: membrane and oxidative stress. ACS Nano. 2011;5(9):6971-6980.

57. Li SJ, Deng DH, Shi Q, Liu SR. Electrochemical synthesis of a graphene sheet and gold nanoparticle-based nanocomposite, and its application to amperometric sensing of dopamine. Microchim Acta. 2012;177: 325-331.

58. Gao J, Liu F, Liu Y, Ma N, Wang Z, Zhang X. Environment-friendly method to produce graphene that employs vitamin $\mathrm{C}$ and amino acid. Chem Mater. 2010;22(7):2213-2218.

59. Li B, Zhang X, Li X, et al. Photo-assisted preparation and patterning of large-area reduced graphene oxide- $\mathrm{TiO}_{2}$ conductive thin film. Chem Commun (Camb). 2010;46(20):3499-3501.

60. Guo S, Wen D, Zhai Y, Dong S, Wang E. Platinum nanoparticle ensemble-on-graphene hybrid nanosheet: one-pot, rapid synthesis, and used as new electrode material for electrochemical sensing. ACS Nano. 2010;4(7):3959-3968.

61. Schrand AM, Dai L, Schlager JJ, Hussain SM, Osawa E. Differential biocompatibility of carbon nanotubes and nanodiamonds. Diamond and Related Materials. 2007;16(12):2118-2123.

62. Mejías Carpio IE, Santos CM, Wei X, Rodrigues DF. Toxicity of a polymer-graphene oxide composite against bacterial planktonic cells, biofilms, and mammalian cells. Nanoscale. 2012;4(15):4746-4756.

63. Wojtoniszak M, Chen X, Kalenczuk RJ, et al. Synthesis, dispersion, and cytocompatibility of graphene oxide and reduced graphene oxide. Colloids Surf B Biointerfaces. 2012;89:79-85.

64. Chen GY, Pang DW, Hwang SM, Tuan HY, Hu YC. A graphene-based platform for induced pluripotent stem cells culture and differentiation. Biomaterials. 2012;33(2):418-427.

65. Ruiz ON, Fernando KA, Wang B, et al. Graphene oxide: a nonspecific enhancer of cellular growth. ACS Nano. 2011;5(10):8100-8107.

66. Park J, Grayfer ED, Jung Y, et al. Photoluminescent nanographitic/ nitrogen-doped graphitic hollow shells as a potential candidate for biological applications. J Mater Chem B. 2013;1:1229-1234.

67. Cheng C, Nie S, Li S, et al. Biopolymer functionalized reduced graphene oxide with enhanced biocompatibility via mussel inspired coatings/ anchors. J Mater Chem B. 2013;1:265-275.

68. Li M, Wang Y, Liu Q, et al. In situ synthesis and biocompatibility of nano hydroxyapatite on pristine and chitosan functionalized graphene oxide. J Mater Chem B. 2013;1:475-484.

69. Ryoo SR, Kim YK, Kim MH, Min DH. Behaviors of NIH-3T3 fibroblasts on graphene/carbon nanotubes: proliferation, focal adhesion, and gene transfection studies. ACS Nano. 2010;4(11):6587-6898.

70. Lee JH, Park J, Yoon OJ, et al. Amine-modified single-walled carbon nanotubes protect neurons from injury in a rat stroke model. Nat Nanotechnol. 2011;6(2):121-125.

71. Matsumoto K, Sato C, Naka Y, Whitby R, Shimizu N. Stimulation of neuronal neurite outgrowth using functionalized carbon nanotubes. Nanotechnology. 2010;21(11):115101.

72. Wang W, Fishman HA, Dai H, Harris JS. Neural stimulation with a carbon nanotube micro electrode array. Nano Lett. 2006;6(9):2043-2048.

73. Gurunathan S, Han JW, Eppakayala V, Kim JH. Green synthesis of graphene and its cytotoxiceffects in human breast cancer cells. Int $J$ Nanomedicine. 2013;8:1015-1027. 
International Journal of Nanomedicine

Dovepress

\section{Publish your work in this journal}

The International Journal of Nanomedicine is an international, peerreviewed journal focusing on the application of nanotechnology in diagnostics, therapeutics, and drug delivery systems throughout the biomedical field. This journal is indexed on PubMed Central, MedLine, CAS, SciSearch $\AA$, Current Contents ${ }^{\circledR} /$ Clinical Medicine,

Journal Citation Reports/Science Edition, EMBase, Scopus and the Elsevier Bibliographic databases. The manuscript management system is completely online and includes a very quick and fair peer-review system, which is all easy to use. Visit http://www.dovepress.com/ testimonials.php to read real quotes from published authors.

Submit your manuscript here: http://www.dovepress.com/international-journal-of-nanomedicine-journal 